\title{
Apontamentos para o estudo da identidade artística
}

Antônio Vargas*

Nos últimos anos, as transformações tecnológicas que promoveram as dinamizações econômicas através dos fluxos de capitais produziram importantes e bruscas alterações nos comportamentos e nas práticas do trabalho, em especial no tópico estabilidade. Fato semelhante também ocorreu no que diz respeito à estrutura familiar, mas preponderantemente como conseqüência das reivindicações feministas e dos movimentos de direitos dos homossexuais.

Por estes motivos, entre outros, nos últimos anos um fenômeno constante em várias áreas de conhecimento tais como educação, sociologia, antropologia e filosofia têm sido pensar o conceito de identidade, questionando-o como algo monolítico. E igualmente pertinente é a aplicação destas considerações ao estudo dos processos constitutivos da identidade artística.

\section{Origem, trânsito e ascensão social: A obra como meio, o mercado e o mito.}

Creio que não há dúvida entre os que estudam os processos de construção da identidade artística, sobre a importância do mercado enquanto espaço no qual se dá o jogo de aceite e rejeição das práticas artísticas .Toda a pessoa que opta por tornar-se artista já possui uma bagagem cultural que é resultado de suas relações sociais, de sua história de vida. Mas isto não significa que o artista pretenda que sua prática se circunscreva apenas aos limites destas relações sociais. A aceitação de suas práticas por parte de um coletivo mais amplo do que aquele que constitui sua teia de relações pessoais é sempre desejada e, veremos, necessária. Maior importância possui para aqueles artistas não que não nascem no berço de uma família relacionada ou inserida no sistema de arte. Geralmente, a realização desta necessidade implica em obter o reconhecimento de pessoas de estratos so-

*Antônio Vargas, Pós-Doutorado Universitat de Barcelona, UB, Espanha, artista plástico, professor do Programa de Pós-Graduação em Teatro da UDESC. 
ciais mais elevados o que por sua vez traz, além de benefícios econômicos, reconhecimento e destaque junto ao seu coletivo de relações. Contribui para sua ascensão social na medida em que o coloca em melhor posição nas negociações simbólicas por ser visto como um intermediário entre diferentes realidades sociais. É absolutamente natural, portanto, que o artista busque o reconhecimento de indivíduos e instituições que representam os estratos mais elevados da pirâmide social. É em meio a este jogo que é negociada a aceitação da prática artística e através dele que a identidade artística se constrói. Perguntas que pesquisas de campo podem contribuir a compreender são, por exemplo: Em que medida o desejo de representar valores culturais de origem são abandonados em detrimento de valores representativos dos segmentos sociais que o artista deseja conquistar? Que fatores materiais e simbólicos são determinantes para estas transformações? $\mathrm{E}$ que mecanismos ou fatores atuam como elementos aglutinadores entre os desejos de ascensão e os de representação de sua origem ? Tais questões estão relacionadas a conceitos como os de semelhança e diferença.

HALL (in da Silva,2004:104) recorda que para a crítica descontrutivista o conceito de identidade se revela como uma "idéia que não pode ser pensada da forma antiga, mas sem a qual certas questões-chave não podem ser sequer pensadas". Mas Hall não deixa de recordar que as questões relativas a identidade podem ser pensadas tanto pela análise das práticas discursivas como pela dos processos de subjetivação, sendo neste último caso, mais adequado pensarmos em identificação que propriamente em identidade. Neste sentido, e distanciando-se de uma conceituação do senso comum que veria a identificação elaborada a partir do reconhecimento de elementos comuns (origem, características, etc) o autor alia-se à abordagem discursiva que vê a identificação como um processo nunca pleno, sempre inconcluso, sempre "em processo". Por esta razão a identificação é sempre condicional e contigenciada. Assim, ao pensar a identidade incorporando a subjetividade implícita ao conceito de identificação Hall propõe uma reflexão em torno de um conceito não essencialista mas "estratégico e posicional". Por conseqüência - esclarece o autor- esta conceituação não se refere a um "eu coletivo, capaz de estabilizar, fixar ou garantir o pertencimento cultural ou uma 'unidade' imutável que se sobrepõe a todas as outras diferenças - supostamente superficiais." (idem:108).

De fato, nos parece que Hall está correto ao entender que o estudo da identidade não deve se ater ao conceito de "identidade coletiva". Mas no estudo dos processos de construção da identidade artística é preciso ter o cuidado para não jogar fora o bebê junto com a água do banho, pois como enfatiza NEUMANN (1992) o estudo sobre a mitologia artística indica claramente que sua influência na aceitação ou rejeição das práticas artísticas é 
considerável. E a mitologia artística é uma forma de concepção ( e construção) coletiva da identidade! O artista enquanto figura social, é um símbolo, naquele sentido em Cassirer ou Jung definiram, e as histórias que contam suas ações ao longo dos séculos reafirmando modelos de comportamento encontram-se incrustadas na cultura humana, independente de classe social , nacionalidade ou etnia ( KRIS \& KURZ 1982). Mitemas sobre a proteção ou origem divina, o nascimento difícil, precocidade, abandono, encontro com o protetor, domínio técnico, apenas para citar alguns dos principais componentes das narrativas heróicas, encontram-se lautamente registrados em críticas jornalísticas , livros biográficos e catálogos e exercem influência significativa no processo de construção da identidade do artista, pois interferem na aceitação de suas práticas. Apenas a título de exemplo: Em um artigo sobre Cacilda Becker, Luís André do Prado (1998), autor da biografia da atriz brasileira que tem como título Cacilda Becker, Fúria santa demonstra as tendências excepcionais da atriz, que não se originariam no berço da família natural e sim em uma suposta herança divina dos criadores do teatro: os gregos. Diz assim:

"Cacilda nasceu em 1921, numa família sem nenhum histórico artístico". (...) "Primordialmente, a família é originária da Grécia. Tanto que a própria Cacilda acreditava ter descendência direta dos gregos: ' meus avós maternos são alemães e minha avó paterna, italiana, meu avô paterno, grego. Nosso jeito é primitivo - vivemos do instinto, agarramo-nos às coisas, ao jardim. Temos apenas o vício de viajar."(PRADO, 1998:74)

Relacionado ao nascimento surgem os mitemas indicativos da Precocidade. O herói, de criança, e de jovem já revela sua natureza incomum, e da mesma forma o artista revela seu talento.

No mesmo texto, um pouco a frente, PRADO se serve deste mitema quando diz que Cacilda:

“ (...) integrou pela primeira vez um elenco teatral sem nunca ter assistido a uma peça" (p.74) "Aos 9 anos, apresentou-se num palco pela primeira vez, numa festa de colégio, ainda em Pirassununga. Isso virou um hábito: além de dançar em casa para "espantar a fome", em toda festa de encerramento do ano letivo, do primário ao secundário, lá estava Cidinha (apelido de infância) com a dança inventada por ela mesma." (1998:77)

De forma semelhante, EICHENBERG ao falar do teatrólogo e diretor 
"Brook fez sua primeira montagem de Hamlet aos 7 anos de idade, quando, com a ajuda de marionetes de papelão, encenou para seus pais a conhecida tragédia do príncipe da Dinamarca."(2002:115)

Agora vejamos: inúmeras crianças encenam e quando adultos seguem outras profissões com poucas relações com a arte. Mas no texto a afirmação deste fato (real ou não) de sua biografia auxilia no reconhecimento das qualidades heróico-artísticas, e estimula o leitor a "entender e aceitar" as qualidades artísticas da prática. Para alguns, estes fatos não passariam de um aspecto anedótico, sem maiores repercussões no estudo da identidade artística. Mas uma análise mais acurada revelaria o equívoco desta desconsideração.

\section{Identidade e diferença.}

As considerações sobre o "transito" ou "negociação" do artista com os diferentes estratos sociais mostram uma questão importante no processo de construção da identidade artística : as relações entre "centro-periferia". É na busca de um maior reconhecimento que o artista migra da cidade menor para a maior; do interior do estado para a capital, de uma capital com menor mercado consumidor para outra com maior e de um país periférico culturalmente para outros países com maiores potencialidades de repercussão artística. E nestes deslocamentos as identidades regionais e nacionais interferem nos processos de negociações simbólicas que geram aceitação ou rejeição das práticas artísticas de uma forma muito mais significativa do que nas relações que se estabelecem dentro da cidade de origem do artista, isto é, naquela na qual ele inicia sua caminhada para o reconhecimento. $\mathrm{O}$ artista que inicia sua carreira profissional na cidade de Chapecó, interior de SC e que migra para a Capital do Estado, Florianópolis, em princípio, enfrentará uma situação semelhante a do artista que iniciou sua carreira em Florianópolis e migra para a capital São Paulo, por exemplo, pois ambos estarão se deslocando de centros de menor para maior consumo artístico. Mas também será semelhante à situação do artista brasileiro ou argentino que migra para as grandes capitais da Europa ou EEUU. Assim sendo, os problemas que enfrentarão serão grosso modo semelhantes no que tange a esta questão. E as causas destes problemas derivam de aspectos concretos e simbólicos. Concretos porque o conhecimento tende a se concentrar nos grandes centros econômicos e no campo da arte isto não é diferente. $A$ riqueza econômica gera o consumo artístico e estimula o debate e as transformações da área, pois fomenta viagens, exposições e publicações. 
Conseqüentemente, aquele que reside longe do centro enfrenta mais dificuldades para acompanhar o debate e as transformações mais recentes das práticas artísticas. Possui maior dificuldade de acesso a galerias, teatros e outros espaços de veiculação. Sua superação implica em uma maior exigência de tempo e recursos para deslocamentos aos centros nos quais ocorre o debate (seja Porto Alegre, São Paulo, New York, Barcelona ou Londres) os quais implicam em outros gastos como hospedagem, aquisições diversas, etc as quais chocam com a realidade do artista que justamente por atuar em um mercado menor obtém uma receita também menor com sua prática artística. Daí reside a leitura - não obrigatoriamente correta - que o artista que vem do interior esta menos preparado que o artista que reside na capital. Esta leitura ocorre igualmente quando o artista migra de uma capital "menor" para uma maior (eixo Rio-São Paulo, p.e.) ou de um país periférico para os grandes centros culturais do exterior. O eventual equívoco decorre do fato de que a avaliação se apóia unicamente sobre o tamanho do mercado de origem do artista, seja das cidades do estado, das capitais ou dos países, sem levar em conta outros fatores como a história de vida do artista. No entanto, eventuais equívocos confirmam a regra, como toda exceção.

Mas esta leitura também é simbólica, porque esta co-implicada com as imagens ancestrais do centro e da cidade nas quais o que esta fora do centro, nas aforas das muralhas da cidade é o terrorífico, o lugar em que habita o deus Pan e conseqüentemente, o lugar onde o pânico e o caos se instalam. Imagens, por certo, em franco confronto com a realidade dos grandes centros urbanos dos países periféricos nas quais o caos e o pânico já habitam o próprio interior das cidades. Mas são imagens poderosas e ainda presentes no imaginário coletivo. Cabe ressaltar, porém, que este tipo de simbolismo, assim como os tipos de problemas vividos pelos artistas em suas migrações territoriais não se aplicam as identidades construídas através das práticas artísticas que se desenvolvem exclusivamente na internet. Estas, de fato, pela sua singularidade e novidade pleiteiam reflexões e estudos específicos, as quais neste artigo não serão tratadas, mas que futuramente pretendemos abordar.

A imagem formulada sobre o artista migrante é simbólica também, porque é uma imagem mitológica, ou seja, decorre de uma ação que encontra similar nas ações narradas pelas mitologias heróicas sob as quais se constrói a mitologia artística. Neste caso, a migração para outra cidade ou centro corresponde aos mitologemas das viagens, da agonística e do aprendizado heróico. Nesta etapa da vida do herói, ampliam-se em todos os sentidos, os campos de aprendizagem e de experiência. CAMPBELL (1993) sublinha que nesta fase as dificuldades são muito freqüentes na jornada do herói, porém 
elas funcionam como provas que testam sua inteligência e perspicácia de superação.

TRINDADE (2003) em artigo sobre a atriz Juliana Carneiro da Cunha nos diz:

“(...) em 1970, mudou-se para Paris, e o coreógrafo Maurice Béjart passou a ser seu novo mestre no centro de Formação do Intérprete Total..." "Juliana trocou o sucesso profissional e financeiro cada vez mais certo no Brasil pelo desemprego e anonimato em Paris." (2003: 108)

Como se vê, o mito ensina que as viagens representam um período de grande aprendizagem na vida dos artistas. Período este no qual adquirem um grande domínio do exercício de suas funções. Sob esta ótica, por mais difícil ou mal fadada que seja a experiência vivida pelo artista no seu deslocamento, esta sempre poderá terminar de forma positiva se o artista retornar ao seu lugar de origem, pois desta forma se fechará o círculo mítico da partida-aprendizado-retorno. E a conseqüência é que em seu retorno será reconhecido não apenas pelo aprendizado que adquiriu em sua aventura, mas principalmente pelo fato de ter retornado para compartilhá-lo com o seu coletivo.

Deve-se ter presente que a leitura que institui a "diferença " entre o artista local e o artista migrante ao ser simbólica é classificatória e portanto possui uma repercussão social. Como recorda WOODWARD (2000)

As identidades são fabricadas por meio da marcação da diferença. Essa marcação da diferença ocorre tanto por meio de sistemas simbólicos de representação quanto por meio de exclusão social. A identidade, pois, não é o oposto da diferença: a identidade depende da diferença. Nas relações sociais, essa forma de diferença - a simbólica e a social - são estabelecidas, ao menos em parte, por meio de sistemas classificatórios. Um sistema classificatório aplica um princípio de diferença a uma população de uma forma tal que seja capaz de dividi-la ( e a todas as suas características) em ao menos dois grupos opostos - nós/eles (por exemplo, servos e croatas); eu/outro.(2000:39,40)

Em sua junção simbólico-social a aplicação de um princípio classificatório de diferença apoiado sobre uma lógica binária implica obrigatoriamente que um dos termos seja inferiorizado. Neste caso, o artista que migrou de um centro pequeno ao retornar pode vir a ser supervalorado frente ao artis- 
ta local já que este último pode vir a ser considerado como aquele que não saiu, o que não possui outras vivências.

Pode-se observar que o elemento mítico atua assim como um "restaurador" e "instaurador" da identidade artística que se fragiliza no processo migratório quando este não gera um maior inserção mercadológica ou quando frustra alguma das expectativas do artista.

Outras ações decorrentes da prática artística e que se encontram corelacionadas com a mitologia artística, tais como o entendimento de domínio técnico, merecem uma atenção especial por suas implicações junto aos diferentes estratos culturais e as conseqüentes reações de aprovação ou rejeição das obras artísticas. Mas a necessidade de uma atenção singular apenas reforça a tese de que a mitologia artística se constitui em um paradoxo que deve ser considerado no estudo dos processos de construção da identidade do artista.

\section{Bibliografia}

CAMPBELL, Joseph. O herói de mil faces. São Paulo: Cultrix, 1993

CASSIRER,Ernst. Esencia y efecto del concepto de símbolo. Ed. FCE, México, 1989

EICHENBERG, Fernando. A Matéria de Hamlet. In revista Bravo! SP. Junho de 2002. Ano 5. N. 57

HALL, Stuart. Quem precisa da Identidade? In Identidade e diferença: A perspectiva dos estudos culturais. Org. Tomaz Tadeu da Silva, Editora Vozes, RJ. 2000

KRIS, E \& KURZ,O. La leyenda del artista. Madrid:Catedra,1982

NEUMANN, Eckhard. Mitos de artista. Madrid:Técnos,1992

PRADO, André L. Por falar nisso, viva Cacilda Becker! Bravo , SP, Setembro de 1998. N.12

TRINDADE, Mauro. De volta pra Casa. In revista Bravo! Agosto de 2003.

VARGAS, A. C.:

- O símbolo no estudo da hierofania estética. PERISCOPE MAGAZINE. Internet: , v.1, 2001. http://www.casthalia.com.br/casthaliamagazine/casthaliamagazine1.htm

- Antropologia simbólica:hermenêutica do mito do artista nas artes plásticas In: As questões do sagrado na arte contemporânea da América Latina ed.Porto Alegre : Editora da Universidade UFRGS, 1997, p. 55-67.

- A ruptura contemporânea com as aporias vanguardistas na cons- 
trução de um novo paradigma estético-social. Porto Arte-Revista do mestrado da UFRGS. Porto Alegre: , v.8, p.81 - 88, 1994. .

- A liberdade de criação e a cultura popular. Porto Arte- Revista do Mestrado em Artes Visuais da UFRGS. , v.6, p.16 - 24, 1993.

WOODWARD, Kathryn. Identidade e diferença: uma introdução teórica e conceitual. In Identidade e diferença: A perspectiva dos estudos culturais. Org. Tomaz Tadeu da Silva, Editora Vozes, RJ. 2000 